\title{
Onlay versus Sublay Mesh Repair for Ventral Hernia
}

\author{
Aly Saber ${ }^{1}$, Emad K. Bayumi \\ ${ }^{1}$ Port-Fouad General Hospital, Port-Fouad, Egypt \\ ${ }^{2}$ General Surgery, Medical Academy Named After S.I. Georgiesky of Crimea Federal University, Crimea, Russia
}

Email address:

Alysaber54@gmail.com (A. Saber), Emadsurg666@hotmail.com (E. K. Bayumi)

\section{To cite this article:}

Aly Saber, Emad K. Bayumi. Onlay Versus Sublay Mesh Repair for Ventral Hernia. Journal of Surgery. Special Issue: Abdominal Surgery: Toward the Best. Vol. 4, No. 1-1, 2015, pp. 1-4. doi: 10.11648/j.js.s.2016040101.11

\begin{abstract}
Introduction: Ventral hernia repair is among the most common surgical operations performed worldwide and the two operative techniques most frequently used in case of ventral hernia are the onlay and sublay repair. However, it remains unclear which technique is superior. The aim of this study was to compare the outcome of the onlay versus sublay mesh repair for ventral hernia. Patients and Methods: A total of 200 patients with paraumbilical, epigastric and supraumbilical incisional hernias were divided into main two groups; A; onlay mesh repair and B; sublay mesh repair. End Points: The primary end point of the study was recurrence of the hernia, defined as a clinically detectable characteristic swelling and diagnosed by the two authors. The secondary end points were operative time, drainage time, seroma formation and purulent wound infection. Results: The mean operative time for onlay repair was $67.04 \pm 13.19$ minutes while in sublay group was $93.26 \pm 24.94$ minutes ranged from 60 to 140 minutes. As regard the drainage time, the mean total time in days was $7.47 \pm 1.7$ days in onlay repair while in sublay group was $4.5 \pm 1.1$ days. Seroma formation after suction drain removal was observed in $6 \%$ patients in group A and in $2 \%$ in group B. Purulent wound infection was observed in $8 \%$ and $4 \%$ patients in group A and B respectively treated with dressing and proper antibiotic according to culture tests. Disease recurrence was observed in $8 \%$ and $3 \%$ patients of group A and B respectively. Conclusion: Sublay mesh repair is a good alternative to onlay mesh repair that may be applicable to all forms of ventral hernia. The mesh related overall complication rate is low such as drainage time, seroma formation and wound infection as well as the low recurrence rate. The authors concluded for trials on sublay mesh repair with a large number of cases and a longer period of follow-up.
\end{abstract}

Keywords: Mesh Repair, Ventral Hernia, Onlay, Sublay

\section{Introduction}

Ventral hernia such as para-umbilical and epigastric hernias are among the most common surgical problems as well as the most common surgical operations performed worldwide [ 1]. The incidence of post-operative wound infection and wound-related complications due to mesh repair aimed at continuing research into the optimal method of treatment of these hernias [2,3]. The two operative techniques most frequently used in case of ventral hernia are the onlay and sublay repair. However, it remains unclear which technique is superior [4]. According to some researchers, the sublay technique has proven much more effective than the onlay with low recurrence rates and minimum rates of complications [5,6]. Among its disadvantages are the complexity of the surgery, longer duration of surgery and likely persistence of chronic abdominal pain [5]. The aim of this study was to compare the outcome of the onlay versus sublay mesh repair for ventral hernia.

\section{Patients and Methods}

\subsection{Patients}

A total of 200 patients with paraumbilical, epigastric and supraumbilical incisional hernias were enrolled to the present study with the period from April 2002 to November 2009. Patients were divided into main two groups; A and B. Group A patients were subjected to onlay mesh repair and Group B patients were subjected to sublay mesh repair. The age of Group A patients ranged between 32 and 60 years with the mean as $46.38 \pm 10.58$ while in group B was $47.16 \pm 10.4$. Patients with infraumbilical incisional hernias or those presented with strangulation were excluded from the study. 


\subsection{Randomization}

Randomization was performed prior to study commencement as follows: Opaque envelopes were numbered sequentially from 1 to 200 . A computer-generated table of random numbers was used for group assignment; if the last digit of the random number was from 0 to 4 , assignment was to Group A (onlay mesh repair), and if the last digit was from 5 to 9 , assignment was to Group B (sublay mesh repair).The assignments were then placed into the opaque envelopes and the envelopes sealed. As eligible participants were entered into the trial, these envelopes were opened in sequential order to give each patient his or her random group assignment. The envelopes were opened by the operating surgeon after patient consent and just prior to surgery.

\subsection{Surgical Teams \& Study Sites}

Operations were performed in Port-Fouad general hospital, Port-Fouad, Port-Said, Egypt and in department of general and gastroenterology surgery, Crimean medical academy named after S.I. Georgievsky, Crimean federal university named after V. I. Vernadsk, Russia.

\subsection{Ethical Consideration}

Written consents were obtained from all patients before the study. The steps of both operative interferences were explained to all patients. The local ethics committee had approved all operative procedures. Ethical approval for this study was granted by the ethical review committee under supervision of the general director of Port-Fouad general hospital, Port-Fouad, Port-Said, Egypt.

\subsection{End Points}

The primary end point of the study was recurrence of the hernia, defined as a clinically detectable characteristic swelling and diagnosed by the two authors. The secondary end points were operative time, drainage time, seroma formation and purulent wound infection.

\subsection{Statistical Analysis}

The statistical tests were run on acompatible personal computer using the Statistical Package for Social Scientists (SPSS) for windows 15. The values were expressed as means \pm standard errors of deviation. The mean values of the groups were compared by one-way analysis of variance (ANOVA) and paired comparisons of the groups were done using the paired student $t$ test. $\mathrm{P}<0.05$ was considered significant.

\subsection{Operative Technique}

\section{A. Onlay mesh repair}

The onlay repair was done under general anaesthesia with skin incision over the bulge or the defect. Using blunt dissection, both the rectus sheath and the defect containing the hernia contents were identified. The hernia sac was clearly dissected and the contents were removed and the margins of the defect were held by Kocher forceps. The sac was dealt with and its contents were reduced into the abdominal cavity. With non-absorbable suture, the defect in the linea alba was closed and a proline mesh of adequate size was placed on the rectus sheath and fixed with stitches. Hemostasis was secured and wound was closed over a suction drain. A dose of broad-spectrum antibiotic was given prior to anaesthesia [1].

B. Sublay mesh repair

The principles of the preperitoneal or sublay mesh repair included two main steps; mesh placement deep to the recti muscles and mesh extension well beyond the hernia defect. After the sac was being dissected and delineated, the defect is opened and the preperitoneal plane is created between the posterior rectus sheath and the rectus muscle for the placement of the mesh. The posterior rectus sheath along with the peritoneum is closed with zero prolenesuture. A proline mesh tailored to the size is placed in the already created plane behind the recti. The mesh is secured with few interrupted $2 / 0$ polypropylene sutures. A suction drain is placed over the mesh The anterior rectus sheath is closed with continuous $1 / 0$ polypropylene sutures. Another drain is placed in the subcutaneous plane and the skin closed. Drains were removed when drainage was less than $20 \mathrm{ml}$ in 24 hours. All the patients were given $1 \mathrm{gm} 3^{\text {rd }}$ generation cephalosporin antibiotic preoperatively at the time of induction and continued till the $5^{\text {th }}$ postoperative day twice daily. The hospital stay of the patients was also recorded down[7].

\section{Results}

There was no statistical difference between both groups regarding their demographic data such as age, sex, special habits and body mass index [BMI] as shown in table1.

Table 1. Showing subdivision of both groups regarding age and body mass index.

\begin{tabular}{lllll}
\hline & & GroupA & GroupB & Pvalue \\
\hline \multirow{2}{*}{ Age } & Age $<50\{32-----49\}$ & $\mathrm{N}=58$ & $\mathrm{~N}=56$ & \multirow{2}{*}{$P \geq 0.05$} \\
& Age $>50\{50-----62\}$ & $\mathrm{N}=42$ & $\mathrm{~N}=44$ & \\
Sex & Male & $\mathrm{N}=48$ & $\mathrm{~N}=50$ & \multirow{2}{*}{$P \geq 0.05$} \\
& Female & $\mathrm{N}=52$ & $\mathrm{~N}=50$ & \\
BMI & $\mathrm{BMI}<25\{22---24.9\}$ & $\mathrm{N}=26$ & $\mathrm{~N}=22$ & \\
& $\mathrm{BMI}<30\{25---29.9\}$ & $\mathrm{N}=44$ & $\mathrm{~N}=50$ & $P \geq 0.05$ \\
& $\mathrm{BMI}>30\{30---34.9\}$ & $\mathrm{N}=30$ & $\mathrm{~N}=28$ & \\
\hline
\end{tabular}

The mean operative time for onlay repair was $67.04 \pm 13.19$ minutes ranged from 45 to 90 minutes while in sublay group was $93.26 \pm 24.94$ minutes ranged from 60 to 140 minutes $\{P \leq 0.0001\}$.

As regard the drainage time, the mean total time in days was $7.47 \pm 1.7$ days \{ranged from5-10 days in onlay repair while in sublay group was 4.5 \pm 1.1 days \{ranged from 3-6 days with significant distribution; $\{P \leq 0.0001\}$.

Seroma formation after suction drain removal was observed in 6 patients in group A that necessitated frequent aspiration under antiseptic techniques until complete evacuation of the formed seroma. In group B, only two patients developed seroma diagnosed by the aid of ultrasonographic imaging and 
treated conservatively.

Purulent wound infection was observed in 8 and 4 patients in group $\mathrm{A}$ and $\mathrm{B}$ respectively treated with dressing and proper antibiotic according to culture tests.

Disease recurrence was observed in $8\{8 \%\}$ and $3\{3 \%\}$ patients of group A and B respectively all over the follow up period with insignificant distribution; $\{P \geq 0.05\}$.

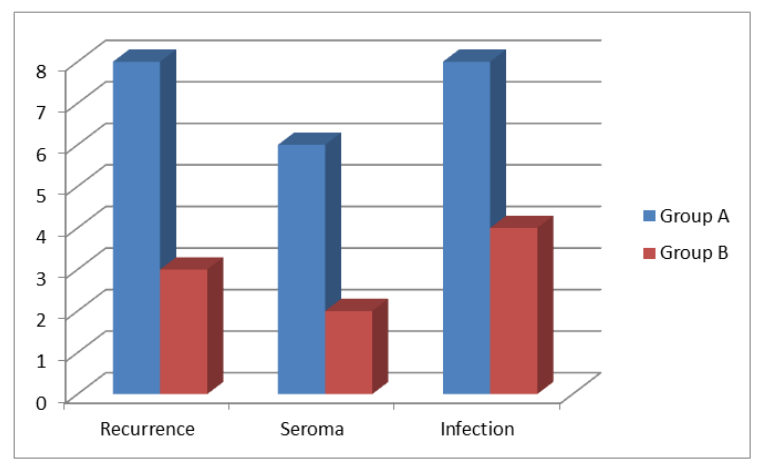

Graph 1. Showed recurrence, seroma formation and wound infection in both groups.

\section{Discussion}

Repair of ventral hernia is an ongoing challenge in surgical practice and a wide spectrum of surgical techniques have been developed ranging from direct suture techniques to the use of various types of mesh to close the defect and strengthen the musculofascial tissues to avoid recurrence [8]. Mesh placement in the preperitoneal, retro muscular sublay position with overlapping the hernia defect in all directions was introduced in the late 1980s [9]. The refinement of sublay technique decreased the recurrence rates and gave better outcome making it to be declared the standard of care of ventral hernias $[9,10]$.

In previous studies, the mean operative time was longer in sublay than onlay techniques due to the time consumed to create the preperitoneal tunnel $[9,10,11]$. Our data came in agreement with these reported studies as the operative time in sublay group patients was much longer in the onlay technique. The time in days consumed to completely drain the discharge resulting from other surgical consequences was significantly longer in onlay than sublay techniques. In agreement with our data, other studies of same interest reported same significant distribution between the onlay and sublay maneuvers $[8,11,12]$.

Seroma formation is a common complication after repair of abdominal wall hernia, which can lead to significant morbidity [13]. In previous studies, the rate of seroma formation in sublay repair is much less than in onlay repair with statistical significant distribution $[8,11,12,14,15]$. Our data came in concordance with those reported according to the previous studies. The incidence of seroma formation is highest following onlay procedures as during anonlay procedure, not only are many blood vessels transected during the required wide mobilization of subcutaneous tissue flaps, but also the insertion of foreign material temporarily establishes an effective barrier between the circulatory system of the subcutaneous tissues and that of the deeper parietal layers [16]. In sublay repair, the retromuscular space is an already existing anatomical plane, requiring no dissection, and the bare posterior surface of the of the rectus muscles is rich in lymphatic is capable to absorb any collecting seroma [17].

Onlay technique is associated with a higher rate of wound infection that remains one of the most common complications of this technique $[11,15,17]$ with reported incidence rate ranging between $6-12 \%[17,18]$. In the present study, we ported lower incidence of wound infection in sublay group patients when compared with onlay group but still with insignificant distribution. Milad and his colleagues reported that the retromuscular plane is highly vascular and helps preventing infection, and if any infection occurs in the subcutaneous plane, it will not affect the mesh, as the mesh is retromuscular in a deeper plane [19].

Hernia recurrence is a distressing event to patient and embarrassing to surgeons and tension free mesh repair is an ideal technique which has decreased the incidence of recurrence [15]. The location of the reinforcement appears to influence outcomes. Underlay or retrorectus mesh placement is associated with lower recurrence rates [20]. The high incidence of recurrence of about $30-50 \%$ after anatomical repair and $1.5-10 \%$ following prosthetic mesh repairs was reported in literatures [11,21,22]. Many studies of same interest compared the recurrence rate in onlay versus sublay repair and found higher incidence in case of onlay maneuver $[7,8,11,22]$. The authors in the present study reported incidence of recurrence in both techniques comparable with those concluded in the previous works. Some researchers reported zero recurrence for sublay techniques and owed this reduced rate of recurrence as a result of the short follow up periods $[11,15,23-25]$.

\section{Conclusion}

Sublay mesh repair is a good alternative to onlay mesh repair that may be applicable to all forms of ventral hernia. The mesh related overall complication rate is low such as drainage time, seroma formation and wound infection as well as the low recurrence rate. The authors concluded for trials on sublay mesh repair with a large number of cases and a longer period of follow-up.

\section{References}

[1] Malik AM. Laparoscopic versus open repair of para-umbilical hernia. Is it a good alternative? J Pak Med Assoc. 2015 ;65(8):865-868.

[2] Gray SH, Hawn MT, Itani Kamal MF. Surgical progress in inguinal and ventral incisional hernia repair. SurgClin N Am 2008; 88: 17-26.

[3] Forbes SS, Eskicioglu C, McLeod RS, Oakrainec A. Meta-analysis of randomized controlled trials comparing open and laparoscopic ventral and incisional hernia repair with mesh. Br J Surg 2009; 96: 851-8. 
[4] Timmermans L, de Goede B, van Dijk SM, Kleinrensink GJ, Jeekel J, Lange JF. Meta-analysis of sublay versus onlay mesh repair in incisional hernia surgery. Am J Surg. 2014 Jun;207(6):980-8.

[5] Strâmbu V, Radu P, Brătucu M, Garofil D, Iorga C, Iorga R, Popa F. Rives technique, a gold standard for incisional hernias -- our experience. Chirurgia (Bucur). 2013 Jan-Feb;108(1):46-50.

[6] Petro CC, Posielski NM, Raigani S, Criss CN, Orenstein SB, Novitsky YW. Risk factors for wound morbidity after open retromuscular (sublay) hernia repair. Surgery. 2015 Jun 20. pii: S0039-6060(15)00371-2. doi: 10.1016/j.surg.2015.05.003. [Epub ahead of print]

[7] Hameed F, Ahmed B, Ahmed A, Dab RH, Dilawaiz. Incisional Hernia Repair by Preperitoneal (Sublay) Mesh Implantation. A P M C, 2009;3 (1): January-June27-31

[8] Ibrahim AH, El-Gammal AS, Mohamed Heikal MM. Comparative study between 'onlay' and 'sublay' hernioplasty in the treatment of uncomplicated ventral hernia. Menoufia Med J 2015;28:11-6

[9] Goda El-Santawy HM, El-Sisy AA, El-Gammal AS, El-Kased AF, Sultan HM. Evaluation of retromuscular mesh repair technique for treatment of ventral incisional hernia. Menoufia Med J 2014;27:226-9

[10] Oh T, Hollands MJ, Langcake ME, Parasyn AD. Incisional hernia repair: a Retrospective review and early experience of laparoscopic repair. Surgery 2004; 74 :50-56.

[11] Aoda FS and Ibrahim AS. Sublay versus onlay mesh repair of ventral hernia. QMJ, 2013; 9 (16):208-213

[12] Ali Q. Murad F, Awan TA, Khan A, Malik AZ. Onlay Versus Sublay Technique of Repairing Ventral AbdominalHernia. JRMC; 2013;17(2):192-194

[13] Martel g, Ahmad J, Taylo Mr. Novel treatment of refractory seroma after incisional hernia repair. Gut 2013;62:a19-a20 doi:10.1136/gutjnl-2013-305143.45

[14] Haytham MA, K Hur, Hirter A, Kim LT, et al. Seroma in ventral incisional herniorrhaphy: incidence, predictors and outcome. Am J Surg 2009; 198 :639-644.
[15] Jat MA, Memon MR, Rind GH. SQA Shah. Comparative evaluation of "Sublay" versus "Inlay" meshplasty in incisional and ventral hernias. Pak J Surg 2011; 27(1):54-58

[16] LehrSC,and Schuricht AL. A Minimally Invasive Approach For Treating Postoperative Seromas After Incisional Hernia Repair. JSLS. 2001 Jul-Sep; 5(3): 267-271.

[17] Saeed N, Iqbal SA, Shaikh BA, Baqai F. Comparison between onlay and sublay methods of mesh repair of incisional hernia. J Post Med Inst 2014; 28(4): 400-3.

[18] Leithy M, Loulah M, Greida HA, Baker FA, Hayes AM. Sublay hernioplasty versus onlay hernioplasty in incisional hernia in diabetic patients. Menoufia Med J 2014;27:353-8

[19] Milad NM, Said SM, Samir M. Comparison between onlay and retromuscular drainless mesh repair for para-umbilical hernia with divarication of recti. Kasr El Aini J Surg 2009;10:11-6.

[20] Albino FP, Patel KM, Nahabedian MY, Sosin M, Attinger CE, Bhanot P. Does mesh location matter in abdominal wall reconstruction? A systematic review of the literature and a summary of recommendations. Plast Reconstr Surg. 2013 Nov;132(5):1295-304.

[21] MehmudAuranga 12.Korenkow M, Sauerland S, Arndt M, BogradL, Neugebauer EAM, Troidl H. Randomized Clinical trials of suture repair, polypropylene mesh or autodermal hernioplasty for incisional hernia. Br J Surg 2002; 89: 50-6.

[22] Bauer JJ, Harris MT, Gorfine SR, Kreel I. Rives stoppa repair of giant incisional hernias. Experience with 57 patients. Hernia 2002; 6: 120-3. 6.

[23] Kharde K, Dogra BB, Panchabhai S, Rana KV, Sridharan S, Kalyan S. A comparative study of onlay and retrorectus mesh placement in incisional hernia repair. Med J DY PatilUniv $2013 ; 6: 258-62$

[24] Elsesy A, Balba MA, Badr M, Latif MA. Retormascular preperitoneal versus traditional onlay mesh repair intreatment of incisional hernias. Menoufiya Med J 2008;21:209-20.

[25] Gleysteen JJ. Mesh-reinforced ventral hernia repair: Preference for 2 techniques. Arch Surg 2009;144:740-5. 